\title{
Comprehensive analysis of the differential expression profile of microRNAs in rats with spinal cord injury treated by electroacupuncture
}

\author{
ZHIDONG ZHOU ${ }^{1}$, HEJIAN LI ${ }^{1}$, HONGCHUN LI ${ }^{1}$, JING ZHANG ${ }^{1}$, \\ KAIWEN FU ${ }^{1}, \mathrm{CAO} \mathrm{CAO}^{1}$, FUMOU DENG ${ }^{1}$ and $\mathrm{JUN} \mathrm{LUO}^{2}$ \\ Departments of ${ }^{1}$ Anesthesiology and ${ }^{2}$ Rehabilitation Medicine, \\ The Second Affiliated Hospital of Nanchang University, Nanchang, Jiangxi 330000, P.R. China
}

Received October 11, 2019; Accepted April 22, 2020

DOI: $10.3892 / \mathrm{mmr} .2020 .11161$

\begin{abstract}
Abnormal microRNA (miRNA) expression has been implicated in spinal cord injury (SCI), but the underlying mechanisms are poorly understood. To observe the effect of electroacupuncture (EA) on miRNA expression profiles in SCI rats and investigate the potential mechanisms involved in this process, Sprague-Dawley rats were divided into sham, SCI and SCI+EA groups $(n=6$ each). Basso, Beattie and Bresnahan (BBB) scoring and hematoxylin-eosin staining of cortical tissues were used to evaluate spinal cord recovery with EA treatment 21 days post-surgery across the three groups. To investigate miRNA expression profiles, 6 Sprague-Dawley rats were randomly divided into SCI and SCI+EA groups ( $\mathrm{n}=3$ in each group) and examined using next-generation sequencing. Integrated miRNA-mRNA-pathway network analysis was performed to elucidate the interaction network of the candidate miRNAs, their target genes and the involved pathways. Behavioral scores suggested that hindlimb motor functions improved with EA treatments. Apoptotic indices were lower in the SCI+EA group compared with the SCI group. It was also observed that 168 miRNAs were differentially expressed between the SCI and SCI+EA groups, with 29 upregulated and 139 downregulated miRNAs in the SCI+EA group. Changes in miRNA expression are involved in SCI
\end{abstract}

Correspondence to: Dr Fumou Deng, Department of Anesthesiology, The Second Affiliated Hospital of Nanchang University, 1 Minde Road, Donghu, Nanchang, Jiangxi 330000, P.R. China

E-mail: dengfumou@163.com

Dr Jun Luo, Department of Rehabilitation Medicine, The Second Affiliated Hospital of Nanchang University, 1 Minde Road, Donghu, Nanchang, Jiangxi 330000, P.R. China

E-mail: luojun1786@163.com

Key words: next-generation sequencing, microRNA profile, spinal cord injury, electroacupuncture, reverse transcription-qPCR physiopathology, including inflammation and apoptosis. Reverse transcription-quantitative PCR measurement of the five candidate miRNAs, namely rno-miR-219a-5p, rno-miR-486, rno-miR-136-5p, rno-miR-128-3p, and rno-miR-7b, was consistent with RNA sequencing data. Integrated miRNA-mRNA-pathway analysis suggested that the MAPK, Wnt and $\mathrm{NF}-\kappa \mathrm{B}$ signaling pathways were involved in EA-mediated recovery from SCI. The present study evaluated the miRNA expression profiles involved in EA-treated SCI rats and demonstrated the potential mechanism and functional role of miRNAs in SCI in rats.

\section{Introduction}

Spinal cord injury (SCI) is a serious neurological injury caused by traffic accidents, falls, or violence-associated injuries, resulting in heavy financial and psychosocial burdens on patients and society (1-4). SCI can lead to impaired sensory and motor functions, autonomic nervous dysfunction and altered mental health (1). To treat SCI more effectively, scientific research has focused on its underlying pathological mechanisms, which involve primary mechanical injury and secondary injury. Secondary injuries are thought to lead to further tissue damage, followed by permanent dysfunction (5). Treatments that reduce secondary injuries can improve the survival rate of spinal cord tissue and reserve the necessary anatomical matrix for functional recovery (6). Due to the complexity of SCI pathogenesis, effective treatments that lead to full recovery have not yet been identified (7). Thus, investigating the mechanism of SCI is invaluable for SCI treatment or recovery. Many pathophysiological events triggered by SCI are tightly regulated by the expression levels of specific genes. Previous studies suggested that changes in gene expression are regulated by microRNAs (miRNAs), a family of short non-coding RNA molecules that repress target mRNA translation (8-10).

miRNAs are non-coding endogenous RNA molecules of about 18-24 nucleotides long that can play vital roles in translational regulation and the suppression of specific mRNAs (11,12). Thus, miRNAs effectively regulate post-transcriptional gene expression in various tissues and 
the development of several diseases (13-15). In addition, changes in functional gene expression have been found to play an important role in secondary damage progression in some degenerative diseases (16-18). As a result, abnormally expressed miRNAs may become new targets for the treatment of various diseases, including traumatic injury, cardiovascular disease or cancer, based on the specific interactions between miRNAs and their target genes $(19,20)$. Moreover, many miRNAs have been demonstrated to play key roles in regulating gene expression, proliferation, inflammation and apoptosis (21). Various neurological diseases have been observed to involve miRNAs $(21,22)$. Furthermore, an increasing number of studies have reported that miRNAs are involved in SCI development $(8,9)$. For example, a previous study revealed that a miR-219-5p inhibitor served a protective role in SCI by regulating the LRH-1 (also known as NR5A2)/Wnt/ $\beta$-catenin signaling pathway (10). The knockdown of miR-21 significantly reduced the inflammatory response at the damaged spinal cord site and promoted motor function recovery (23). A recent study demonstrated that miR-21 was upregulated in neurons following SCI and could reduce neuronal sensitivity to apoptosis by targeting programmed cell death 4 (23). Moreover, miR-137 inhibited inflammatory responses and apoptosis after SCI by targeting MAPK activated protein kinase 2 (24). Another study indicated that miR-199a-5p might protect the spinal cord against ischemia-reperfusion induced injury by negatively regulating endothelin converting enzyme 1 (25). Taken together, these previous studies emphasized that both positive and negative regulators of tissue regeneration were required for optimal control of overall gene expression. Recent findings regarding miRNAs and their specific role in SCI diseases have great significance for the development of efficient treatments and novel specific drugs.

Several novel therapeutic approaches are currently being used for the treatment of patients with SCI, including stem cell therapy and electroacupuncture (EA) (26-28). Both animal experiments and pain investigation have shown that EA has an analgesic effect on chronic pain (29-32). In addition, several previous studies suggested that EA at different frequencies may exhibit varying degrees of analgesia (33-35). To date, EA treatment at the Dazhui and Mingmen acupuncture points have been evaluated for their impact on SCI recovery (36). However, the underlying mechanism of EA in SCI treatment remains unclear. The expression profile of miRNAs in SCI rats and the possible mechanism affected by EA remains to be elucidated.

To the best of the authors' knowledge, the present study is the first to report a comprehensive analysis of the differential expression profile of microRNAs in SCI rats treated with EA. Specific miRNAs were selected and their possible functions and enriched signaling pathways in SCI were systematically analyzed. The present study provides a basis for better understanding the effect of EA on SCI repair and examines how changes in miRNA expression are involved in the molecular mechanisms underlying EA-associated SCI recovery.

\section{Materials and methods}

Animals. All experiments were approved by The Institutional Animal Care and Use Committee of The Second Affiliated
Hospital of Nanchang University (Nanchang, China) and were performed according to the guidelines of The National Institutes of Health Guide for the Care and Use of Laboratory Animals. All efforts were made to minimize the number of animals used and their suffering. A total of 18 male Sprague-Dawley (SD) rats weighing 180-200 g (age, 8 weeks) were obtained from Xipuer-Bikai Laboratory Animals Co., Ltd. All rats were placed in plastic chambers at $22-24^{\circ} \mathrm{C}$ and were provided a commercial diet and water under a 12 -h reversed light-dark cycle before the study. Health and behavior were monitored twice daily. Following a 7-day adaptation, the rats were divided into three groups ( $n=6$ each), a sham group, an SCI model group, and an electroacupuncture group (SCI+EA) to evaluate the effects of EA treatment on SCI. Furthermore, to investigate the miRNA expression profiles using next-generation sequencing (NGS), following pathological assessment of half spinal cords of each group rats [hematoxylin-eosin (HE) staining and ELISA], the other half spinal cords from each rat of the model group (SCI; $n=3$ ) or electroacupuncture group $(\mathrm{SCI}+\mathrm{EA} ; \mathrm{n}=3)$ were used to perform NGS.

Model establishment and EA treatment. The rats were anesthetized by intraperitoneal injection of $100 \mathrm{~g} / \mathrm{l}$ chloral hydrate $(350 \mathrm{mg} / \mathrm{kg})$. Adequate anesthesia was verified based on a lack of response to a nociceptive stimulus. None of the rats exhibited signs of peritonitis, pain or discomfort. Anesthetized rats were placed in a prone position with a lumbar cushion with fixed limbs and head. After shaving and sterilizing the back, cavitation was performed, and the skin was cut along the back median line after routine disinfection. On both sides of the spine, the muscles were separated, and the spinous process was exposed. After determining the location, the spinous process of L4 was removed with fine bone-biting forceps, and the dura mater between the L4 and 5 segments was exposed. Under direct vision, $22 \mathrm{G}$ beveled needles were used to pierce the L4-5 spinal cord segments toward the head along the center of the spinal cord at a $60^{\circ}$ angle to the end of the spine. After $2 \mathrm{sec}$, the needles were removed, and the muscle, subcutaneous fascia and skin were sutured layer-by-layer. An effective puncture injury was determined by tail motion in rats. Spinal cord puncture was not performed in the sham group.

Three days after the injury operation, the SCI+EA group received EA therapy twice daily for three weeks. For EA treatment, GV14 (Dazhui, the large vertebra), GV4 (Mingmen, the 'vital door') and Jiaji points were stimulated. EA stimulation occurred for $20 \mathrm{~min}$ at $60 \mathrm{~Hz}$ and an alternating pulse width of $1.05 \mathrm{sec}$ or $2.85 \mathrm{sec}$, which was sufficient to elicit slight twitching in the hind limbs. For the sham group, acupuncture needles were inserted bilaterally at a point lateral to the aforementioned acupoints without any electrical stimulation. The total duration of the SCI model experiment was 31 days. The animals were then anesthetized by intraperitoneal injection of pentobarbital sodium $(200 \mathrm{mg} / \mathrm{kg})$ after Basso, Beattie and Bresnahan (BBB) score evaluation (37). The anesthetized rats were then decapitated for assuring death. No animals died during the modeling process, and all animals were successfully modeled according to the BBB assessment and HE staining. Tissue samples of the L4-5 spinal cord segments were removed from 6 rats per group after EA stimulation for histological staining and stored at $-80^{\circ} \mathrm{C}$. 
$B B B$ score evaluation and tissue preparation. The BBB method was employed to examine the functional deficits of rats following SCI. The sham group of normal male rats without functional deficits (BBB score, 21) was selected as a control. Hindlimb motor function of rats was assessed at 1, 3, 7 and 21 days after SCI. Following spinal cord surgery, trained observers, who were blind to the experimental conditions, evaluated the grade of each rat according to the BBB open field locomotion test (38). Rats were placed in an open basin, and hindlimb movement, ankle joint walking, trunk movement and coordination were observed for $5 \mathrm{~min}$ to determine the BBB score of each animal. A random selection of 6 rats per group were sacrificed and quickly dissected at 3 weeks after SCI, and the impaired spinal cords were harvested for real-time qPCR, HE staining, and NGS. The tissues were frozen in liquid nitrogen and stored at $-80^{\circ} \mathrm{C}$.

$H E$ staining. After removal, using the aforementioned procedure, tissue samples were fixed in $4 \%$ polyformaldehyde for $30 \mathrm{~min}$ at room temperature and embedded in paraffin. The $5 \mu \mathrm{m}$ paraffin-embedded sections were placed in a $65^{\circ} \mathrm{C}$-constant temperature oven for $30 \mathrm{~min}$ and subsequently dewaxed with xylene I and xylene II for $15 \mathrm{~min}$ at room temperature. The following steps were at room temperature: The dewaxed slices were soaked in 100, 95, 85 and $75 \%$ ethanol for 5 min each and washed with tap water for $10 \mathrm{~min}$. The sections subsequently underwent staining in hematoxylin for $5 \mathrm{~min}$, followed by color separation with ammonium hydroxide for several seconds. Next, the sections were rinsed with water for $15 \mathrm{~min}$ and dehydrated with 70 and $90 \%$ ethanol for 10 min each. Then sections were then stained with eosin for 1-2 min, hydrated in $100 \%$ ethanol for $10 \mathrm{~min}$, cleared with xylene, and finally mounted with neutral gum. The spinal cord tissue structure was observed under a light microscope, at x200 magnification.

ELISA. The assessment of the IL-1 $\beta$ and TNF- $\alpha$ levels in the spinal cord tissues was performed by ELISA, using a rat IL-1 $\beta$ and TNF- $\alpha$ ELISA kit (cat. no. EK0393, BosterBiotech), Briefly, 96-well plates were added the $100 \mu \mathrm{l}$ sample and standard for 3 duplicate samples and incubated for $90 \mathrm{~min}$ at room temperature. Then $100 \mu \mathrm{l}$ biotin-labeled antibodies were added and incubated for $60 \mathrm{~min}$ at room temperature. The plates were washed with PBS for three times, and avidin-biotin-complex added and incubated for $30 \mathrm{~min}$ at room temperature. After further washing, 3,3',5,5'-tetramethylbenzidine substrate solution was added and the plates were incubated in the dark for $20 \mathrm{~min}$. The reaction was stopped by the addition of termination reagent, and the absorbance at 450 and $570 \mathrm{~nm}$ was measured using a microplate reader.

Preparation of small RNA library and NGS. Rats from the SCI and SCI+EA groups ( $\mathrm{n}=3$ in each group) were randomly selected and sacrificed 21 days after SCI, and the impaired spinal cords were harvested for NGS and reverse-transcription-quantitative (RT-q)PCR. The tissues were frozen in liquid nitrogen and stored at $-80^{\circ} \mathrm{C}$. Total RNA was isolated from the spinal cords using TRIzol ${ }^{\circledR}$ reagent (Invitrogen; Thermo Fisher Scientific, Inc.). RNA concentration and quality were evaluated using a Nanodrop ${ }^{\mathrm{TM}}$ instrument (Thermo Fisher Scientific, Inc.) and $1 \%$ gel electrophoresis, respectively. Purified RNA samples were subjected to adapter ligation, cDNA synthesis, PCR amplification, and construction of RNA libraries using the miRNA Library Prep Kit (New England BioLabs, Inc.) according to the manufacturer's protocol. RNA sequencing was then performed on a Hiseq 2500 (Illumina, Inc.). Datasets were generated with a sequencing depth of 50 million reads from the multiplexed samples. The raw data were refined with FastQC (http://www.bioinformatics.babraham.ac.uk/projects/fastqc/; version 0.11.2) (39) to filter out short ( $<15$ nucleotides ) reads by evaluating the quality of sequencing data (including base mass value distribution, mass value location distribution and GC content) and low-quality reads according to base quality value, including a phred quality mean score $>30$ and reads between 18 and $40 \mathrm{nt}$ in length. High-quality reads were screened using miRBase (http://www.mirbase.org/) database to identify known miRNAs.

Analysis of differentially expressed (DE) miRNAs and their target gene prediction. Differential expression of miRNAs in the SCI+EA group and the SCI group, was assessed using the Ebseq 2.0 package $(40)\left(\mathrm{P}<0.05 ; \mid \log _{2} \mathrm{FCl}>1\right.$, where FC indicates fold change). MiRanda (http://miranda. org.uk/) (41) and RNAhybrid (https://bibiserv.cebitec. uni-bielefeld.de/rnahybrid) (42) software was used to predict the target genes of the DE miRNAs. Overlapping genes from RNAhybrid (energy <-25) and MiRanda (score $\geq 150$; energy <-20) were considered as potential targets of miRNAs. Finally, an integrated mRNA-miRNA interaction network was constructed using Cytoscape software (43) (version 3.5.1).

Gene Ontology (GO) and Kyoto Encyclopedia of Genes and Genomes (KEGG) analysis. GO (http://geneontology.org/) analysis, including molecular function, biological process, and cellular component assignment, was conducted to evaluate the functions of the screened targets. Pathway enrichment analysis of the miRNA targets was carried out using KEGG (http://www.genome.jp/kegg/) analysis. $\mathrm{P}<0.05$ was considered to indicate a statistically significant difference.

$R T-q P C R$. Total RNA was isolated from the spinal cords of rats in the SCI and SCI+EA groups 21 days after SCI using TRIzol $^{\circledR}$ reagent (Invitrogen; Thermo Fisher Scientific, Inc.) and reverse transcribed into cDNA using the RevertAid ${ }^{\mathrm{TM}}$ First-Strand cDNA Synthesis kit (Thermo Fisher Scientific, Inc.), as per the manufacturer's instructions. Gene-specific RT primers were used for each miRNA.

RT-qPCR was performed for 45 amplification cycles with the following conditions: $95^{\circ} \mathrm{C}$ for $10 \mathrm{sec}, 60^{\circ} \mathrm{C}$ for $60 \mathrm{sec}$, and $95^{\circ} \mathrm{C}$ for $5 \mathrm{sec}$. FastStart Universal SYBR Green Master mix (Thermo Fisher Scientific, Inc.) was used to amplify cDNA using the ABI Q6 detection system (Applied Biosystems; Thermo Fisher Scientific, Inc.). All reactions were set up in triplicate. Relative quantification and calculations were assessed using the comparative threshold cycle method $\left(2^{-\Delta \Delta \mathrm{Cq}}\right)$ (44). All primers were from Yingbiotech. Primer sequences and are listed in Table I. GAPDH and U6 were used as the internal control for mRNA and miRNA, respectively.

Cell culture. The BV2 microglial cell line was obtained from Procell Life Science \& Technology Co.,Ltd.Cells were cultured 
Table I. Primer sequences.

Primer name

Sequence (5'-3')

\section{U6 F}

U6 R

rno-miR-219a-5p RT

rno-miR-486 RT

rno-miR-128-3p RT

rno-miR-136-5p RT

rno-miR-7b RT

rno-miR-219a-5p F

rno-miR-486 F

rno-miR-136-5p F

rno-miR-128-3p F

rno-miR-7b F

All miRNA-R

GAPDH F

GAPDH R

Sema3a F

Sema3a R

Vangl2 F

Vangl2 R

Gng3 F

Gng3 R

TNF- $\alpha \mathrm{F}$

TNF- $\alpha$ R

IL- $1 \beta \mathrm{F}$

IL-1 $\beta$ R
CGATACAGAGAAGATTAGCATGGC

AACGCTTCACGAATTTGCGT

GTCGTATCCAGTGCGTGTCGTGGAGTCGGCAATTGCACTGGATACGACAGAATTG GTCGTATCCAGTGCGTGTCGTGGAGTCGGCAATTGCACTGGATACGACCTCGGGG GTCGTATCCAGTGCGTGTCGTGGAGTCGGCAATTGCACTGGATACGACAAAGAGA GTCGTATCCAGTGCGTGTCGTGGAGTCGGCAATTGCACTGGATACGACTCCATCA GTCGTATCCAGTGCGTGTCGTGGAGTCGGCAATTGCACTGGATACGACACAACAA GCGGGTGATTGTCCAAACG

GCGGGTCCTGTACTGAGCTG

CGCAGACTCCATTTGTTTTGA

GCGCAGTCACAGTGAACCG

CGCAGTGGAAGACTTGTGATT

AGTGCGTGTCGTGGAGTCG

TGGAGAAACCTGCCAAGTATGAT

TCAAAGGTGGAAGAATGGGAGT

ACATTTTTAAACTGCAGGACTCACA

GAGTCGTGCTGCTCGGTCC

TTCTGCTGGAGCTGCGTCA

AGGAGGGCGGGGTTGTAGA

GGATAAAGGTGTCCAAGGCAGC

GTGGGCACAGGAGTGATGAGG

GCCACCACGCTCTTCTGTCTA

GGGCTACGGGCTTGTCACT

ACAGACCCCAAAAGATTAAGGATT

CCACGGGCAAGACATAGGTAG

miR/miRNA, micro RNA; F, forward; R, reverse; RT, reverse transcription; Sema3a, semaphorin 3A; Vangl2, Van Gogh Drosophila-like planar cell polarity protein 2 ; Gng3, G protein subunit $\gamma 3$; TNF- $\alpha$, tumor-necrosis-factor- $\alpha$; IL, interleukin.

in minimum essential medium (MEM) medium supplemented with $10 \%$ fetal bovine serum and $1 \%$ penicillin-streptomycin (All from Gibco; Thermo Fisher Scientific) at $37^{\circ} \mathrm{C}$ and $5 \% \mathrm{CO}_{2}$, and passaged twice a week.

Cell transfection. The miR-136-5p mimics (5'-ACUCCA UUUGUUUUGAUGAUGGA-3' and 5'-CAUCAUCAAAAC AAAUGGAGUUU-3') and mimics negative control (NC; 5'-UUCUCCGAACGUGUCACGUTT-3' and 5'-ACGUGA CACGUUCGGAGAATT-3') were purchased from Shanghai GenePharma Co., Ltd. Lipofectamine ${ }^{\circledR} 2000$ (Invitrogen; Thermo Fisher Scientific, Inc.) was used to transfect BV2 microglial cells with the $100 \mathrm{nM}$ rno-miR-136-5p mimics or mimics NC. After a 48 -h incubation, cells at $80-90 \%$ confluence were harvested for RNA extraction and reverse transcription. The levels of rno-miR-136-5p expression were detected by RT-qPCR.

Cell Counting Kit-8 (CCK-8) assay. For cell proliferation assays, $2 \times 10^{4}$ BV2 cells per well were seeded in a 96 -well plate. The cells were incubated with $10 \mu \mathrm{l}$ of CCK- 8 reagent (Beyotime Institute of Biotechnology) at $37^{\circ} \mathrm{C}$ for $2 \mathrm{~h}$ at the indicated time point for $0,24,48,72$ and $96 \mathrm{~h}$. The absorbance

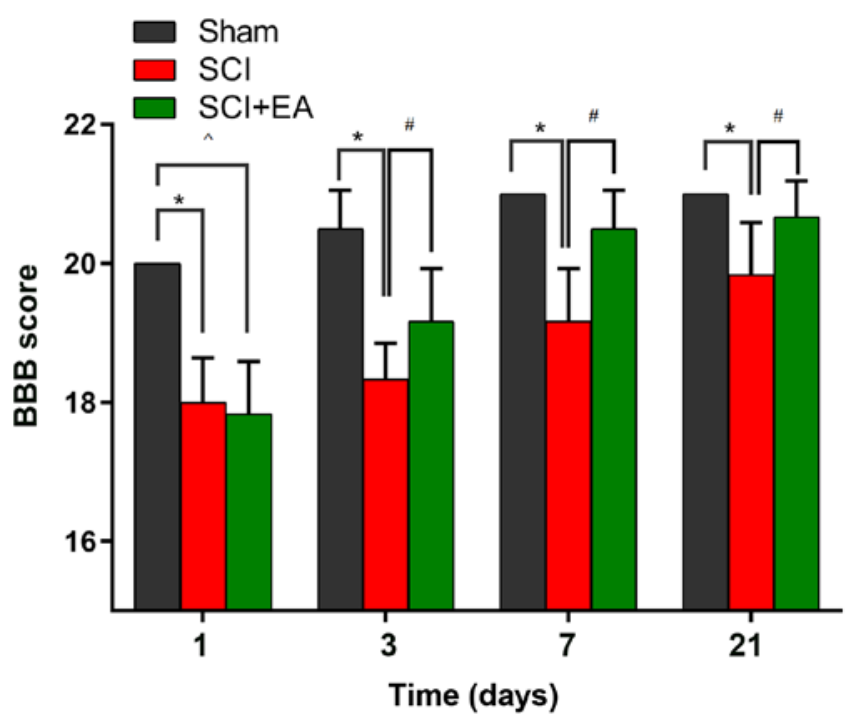

Figure 1. Effect of EA on the motor function of SCI rats. Results of the BBB test in sham, SCI and SCI+EA-treated groups at 1, 3, 7 and 21 days following SCI surgery. The BBB score was significantly lower in the SCI group compared with the sham and SCI+EA groups at 3, 7 and 21 days. Data are presented as the mean \pm SD. BBB, Basso, Beattie, and Bresnahan; SCI, spinal cord injury; EA, electroacupuncture. $n=6$ in each group. ${ }^{*} \mathrm{P}<0.05 \mathrm{SCI}$ vs. sham; ${ }^{\#} \mathrm{P}<0.05$ SCI vs. $\mathrm{SCI}+\mathrm{EA} ;{ }^{\wedge} \mathrm{P}<0.05$ are shown for $\mathrm{SCI}+\mathrm{EA}$ vs. sham. 
A

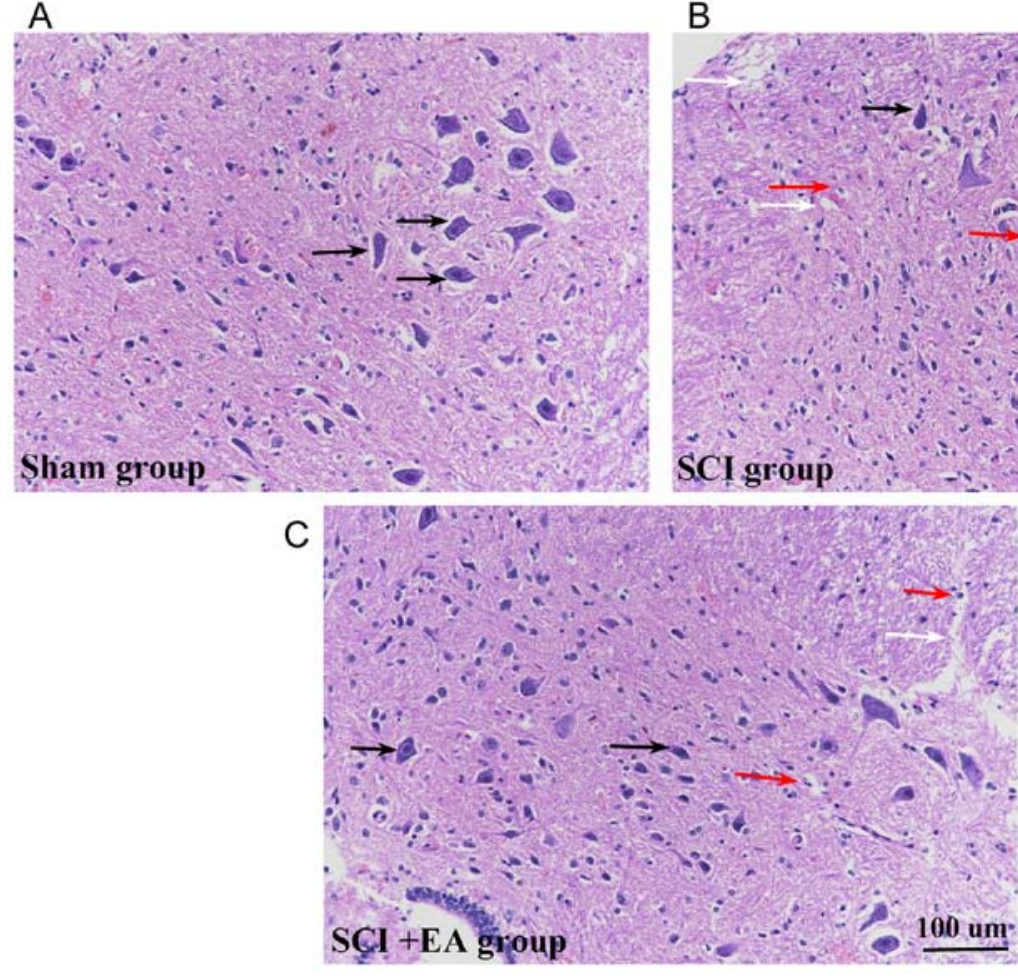

Figure 2. Hematoxylin-eosin staining of SCI rat tissues. Representative morphological photographs under light microscopy after 12 rats with SCI were divided into untreated and EA-treated groups, vs. 6 healthy rats. (A) Sham group. (B) SCI group. (C) SCI+EA group. Black, red and white arrows represent nerve cells, inflammatory cells and tissue vacuoles, respectively. The number of black arrows in sham group and SCI+EA group was more than in SCI group. The number of red and white arrows in SCI group was more than that in sham group and SCI+EA group; $\mathrm{n}=6$ in each group; magnification, $\mathrm{x} 200$. Scale bar=100 $\mu \mathrm{m}$. SCI, spinal cord injury; EA, electroacupuncture.

at $450 \mathrm{~nm}$ was measured with Infinite M1000 instrument (Tecan Group, Ltd.).

Apoptosis analysis. An Annexin V-FITC Early Apoptosis Detection kit (cat. no. C1062; Beyotime Institute of Biotechnology) was used to detect cell apoptosis. Briefly, $48 \mathrm{~h}$ after cell transfection, BV2 microglial cells were harvested with trypsin, re-suspended in annexin V-FITC/propidium iodide, and then incubated for 10-15 $\mathrm{min}$ at room temperature in the dark. A BD FACSVerse ${ }^{\mathrm{TM}}$ flow cytometer (BD Biosciences) was used to assess cell apoptosis rates in different groups according to the instrument's operating protocol. Data were analyzed using WinMDI version 2.5 (Purdue University Cytometry Laboratories; http://www.cyto.purdue. edu/flowcyt/software/Catalog.htm).

Statistical analysis. Data were analyzed using SPSS version 19.0 (SPSS, Inc.) and are presented as the mean \pm SD. Two-group comparisons were performed using unpaired Student's t-test. Multi-group comparisons were analyzed using one-way ANOVA, followed by Tukey's post hoc test. $\mathrm{P}<0.05$ was considered to indicate a statistically significant difference.

\section{Results}

Effects of EA on behavior in SCI rats. In the present study, the potential efficacy of EA treatment in a rat model of SCI was investigated. Motor dysfunction in the lower limbs was evaluated 1, 3, 7 and 21 days after SCI injury, using the $\mathrm{BBB}$ scoring criteria. To determine the time course of the changes in SCI injury, baseline measurements were obtained prior to surgery. The baseline BBB scores on both hind paws did not differ among the three groups (data not shown). After surgery, rats exhibited various degrees of motor dysfunction, indicating successful establishment of the rat SCI model (Fig. 1). In the SCI group, BBB scoring was markedly reduced from $20.00 \pm 0.00$ to $18.00 \pm 0.63$, compared with the values in the sham group $(\mathrm{P}<0.05)$. On day 21 following $\mathrm{SCI}$, the $\mathrm{BBB}$ score was evaluated across all groups. Rats that received EA treatment exhibited significantly higher BBB scores compared with untreated rats following SCI. These results suggested that EA may promote spinal recovery following SCI in rats.

Effects of EA on micromorphology of spinal cords tissues. Morphological analysis of HE-stained sections suggested that spinal cord tissue structures in the sham group were clear and integrated, and that the cells were well-arranged, with large round nuclei and abundant cytoplasm (Fig. 2A). Following the surgical SCI procedure, the structural integrity of the spinal cord was severely compromised, and the contusion injury site showed signs of significant tissue compression. At 21 days post-surgery, HE-stained sections revealed hemorrhage, edema, a progressive increase in inflammatory cells, vacuolar degeneration at the injury site and neuronal damage (Fig. 2B). Signs of hemorrhage and inflammatory cell infiltration remained in the spinal cord tissue, whereas 
A

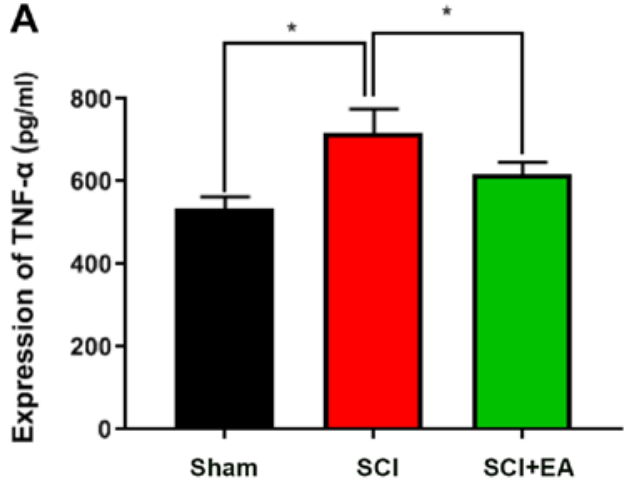

C
B

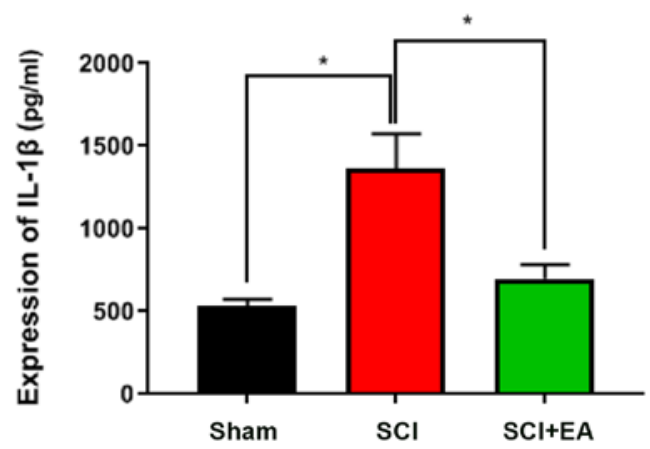

Figure 3. Detection of tissue inflammatory factors. (A) TNF- $\alpha$ and (B) IL-1 $\beta$ levels were detected by ELISA. (C) The relative expression levels of TNF- $\alpha$ and IL-1 $\beta$ were detected by reverse transcription-quantitative PCR. " $\mathrm{P}<0.05$. SCI, spinal cord injury; EA, electroacupuncture; TNF- $\alpha$, tumor necrosis factor- $\alpha$; IL, interleukin.

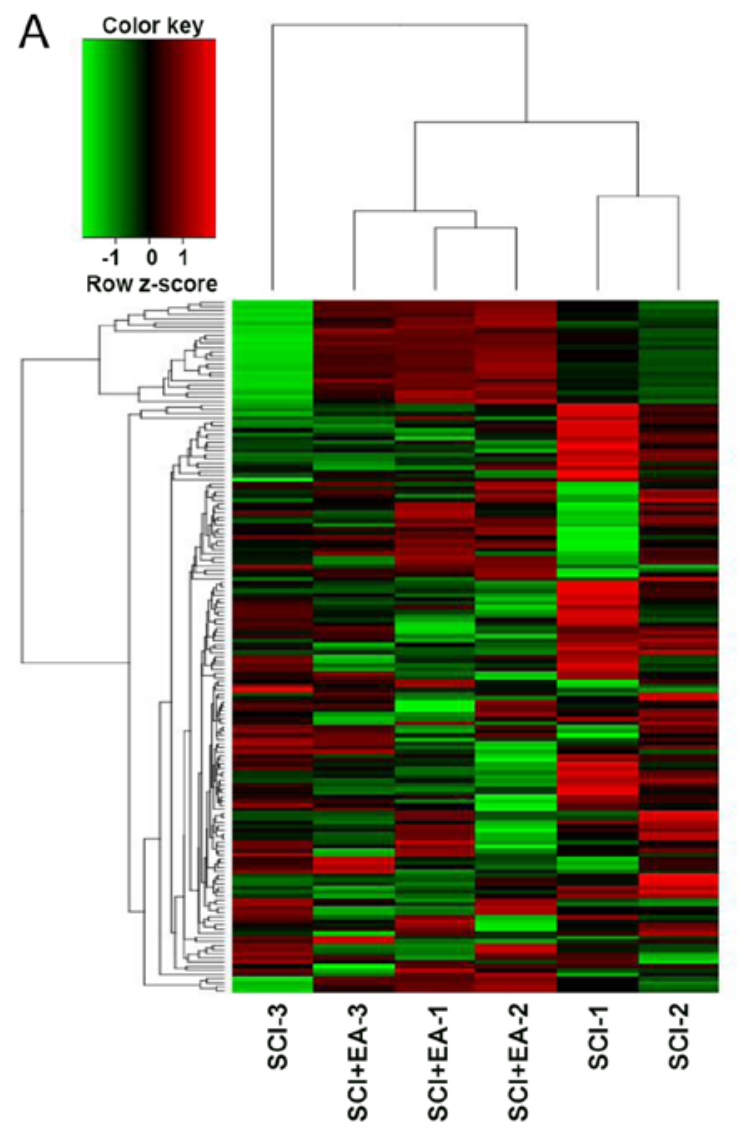

B

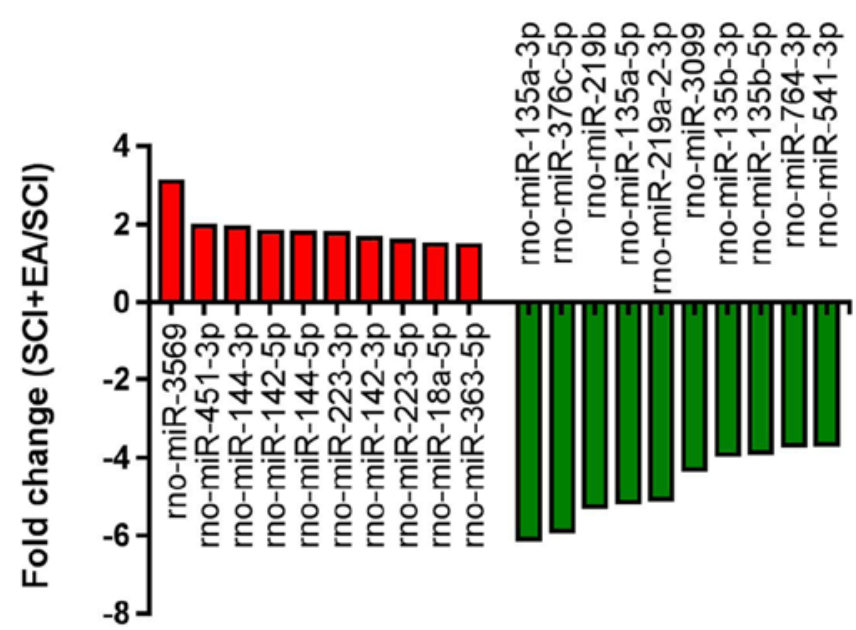

Figure 4. Differential expression of spinal cord tissue miRNAs between rats in the SCI and SCI+EA groups. (A) Heatmap depicting the expression of the differentially expressed miRNAs with upregulated (red) and downregulated (green). Samples and miRNAs have been reordered by hierarchical clustering. (B) Top 20 up- or downregulated differentially expressed miRNAs between SCI+EA and SCI group rats based on miRNA sequencing. SCI, spinal cord injury; EA, electroacupuncture; miRNA, micro RNA. 
A

Top 20 of GO enrichment

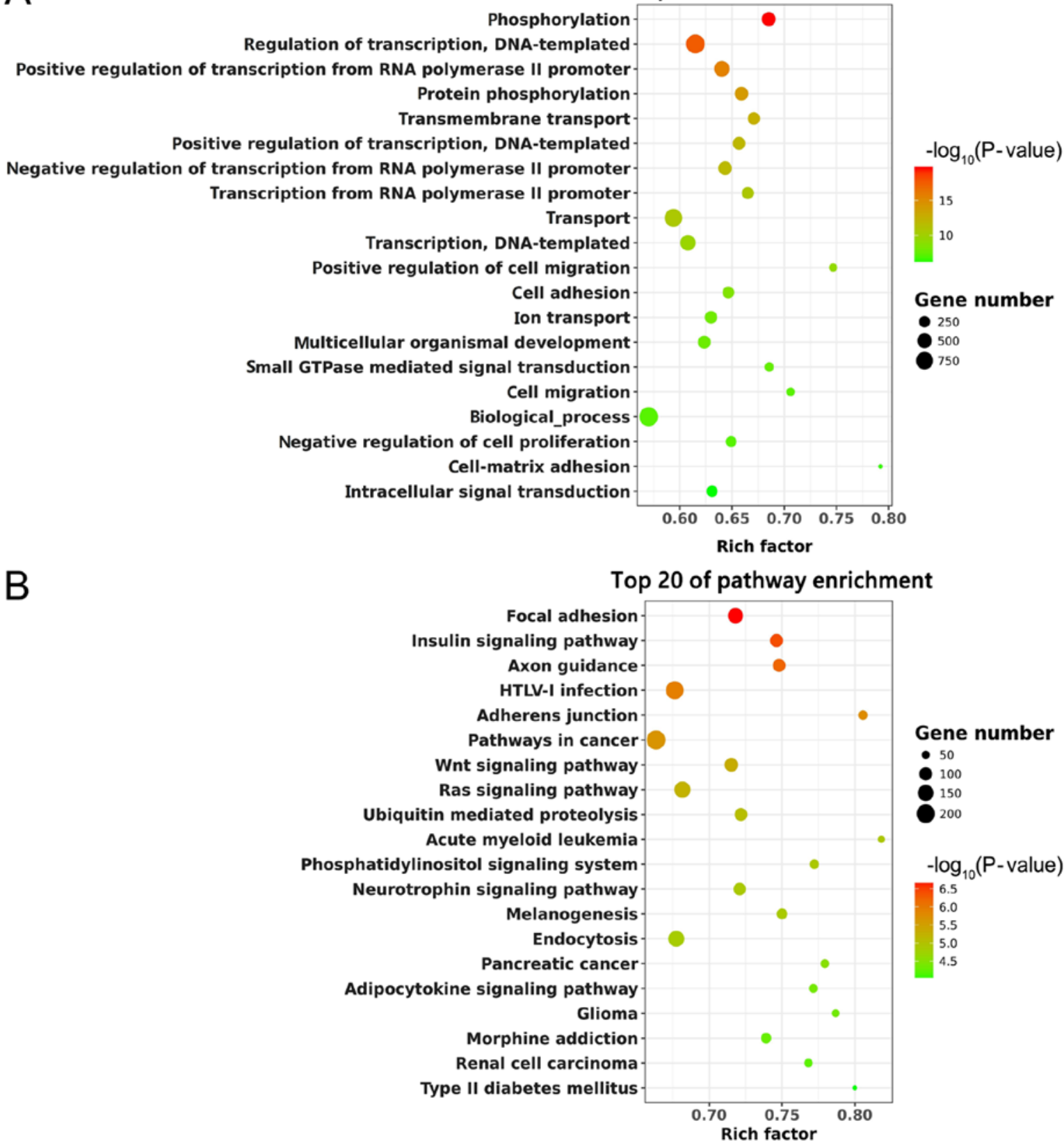

Figure 5. GO and KEGG analyses of the target genes of differentially expressed miRNAs. (A) GO analysis of the significantly enriched target genes. The top 20 significantly enriched items are listed. The degree of GO enrichment was determined by P-value, enrichment factor and miRNA target numbers. Dot sizes and colors indicate the number of target genes and $-\log (\mathrm{P}-\mathrm{value})$, respectively. (B) Pathway enrichment analysis for miRNA targets through KEGG. Enrichment scores are presented as - $\log$ (P-value). GO, Gene Ontology; KEGG, Kyoto Encyclopedia of Genes and Genomes; miRNA, micro RNA.

SCI+EA group tissue sections exhibited the most substantial restoration of neuronal morphology with axonal regeneration (Fig. 2C). While both normal and necrotic cells were present in the sham and SCI+EA groups, the magnitude of necrosis appeared to be decreased in these two groups, compared with the SCI group.

Effects of EA on tissue inflammatory factors. To observe the effect of EA treatment on tissue inflammatory factor expression in SCI rats, TNF- $\alpha$ and IL-1 $\beta$ expression levels were detected by ELISA. Both of these were significantly lower in the SCI+EA treatment group than in the SCI group $(\mathrm{P}<0.05$; Fig. 3A and B). RT-qPCR suggested similar results.
Compared with the SCI group, the relative expression levels of TNF- $\alpha$ and IL-1 $\beta$ in the sham and SCI+EA treatment groups were significantly decreased $(\mathrm{P}<0.05$; Fig. 3C). These results demonstrated that EA treatment could decrease inflammatory factors and inflammation in the spinal cord tissue of rats.

Identification of differentially expressed (DE) miRNAs in SCI rats. To observe the effect of EA treatment on miRNA expression profiles in SCI rats and determine the miRNAs involved in EA treatment, NGS was used to obtain a profile of the miRNAs in spinal cord tissue. In total, 764 miRNAs were identified from the six samples. Among them, 168 miRNAs showed 
Table II. Candidate miRNAs in the SCI and SCI+EA group.

\begin{tabular}{lcccr}
\hline miRNA & $\log _{2} \mathrm{FC}$ & P-value & FDR & Trend \\
\hline rno-miR-219a-5p & -2.194697258 & 0.000086252 & 0.000756832 & Down \\
rno-miR-486 & 1.123062605 & 0.010721736 & 0.038169381 & Up \\
rno-miR-136-5p & -1.824091331 & 0.000020324 & 0.000238909 & Down \\
rno-miR-128-3p & -1.776468827 & 0.000472567 & 0.003271216 & Down \\
rno-miR-7b & -3.300169904 & 0.000000009 & 0.000000364 & Down \\
\hline
\end{tabular}

miR/miRNA, micro RNA; SCI, spinal cord injury; EA, electroacupuncture; FC, fold change; FDR, false discovery rate.

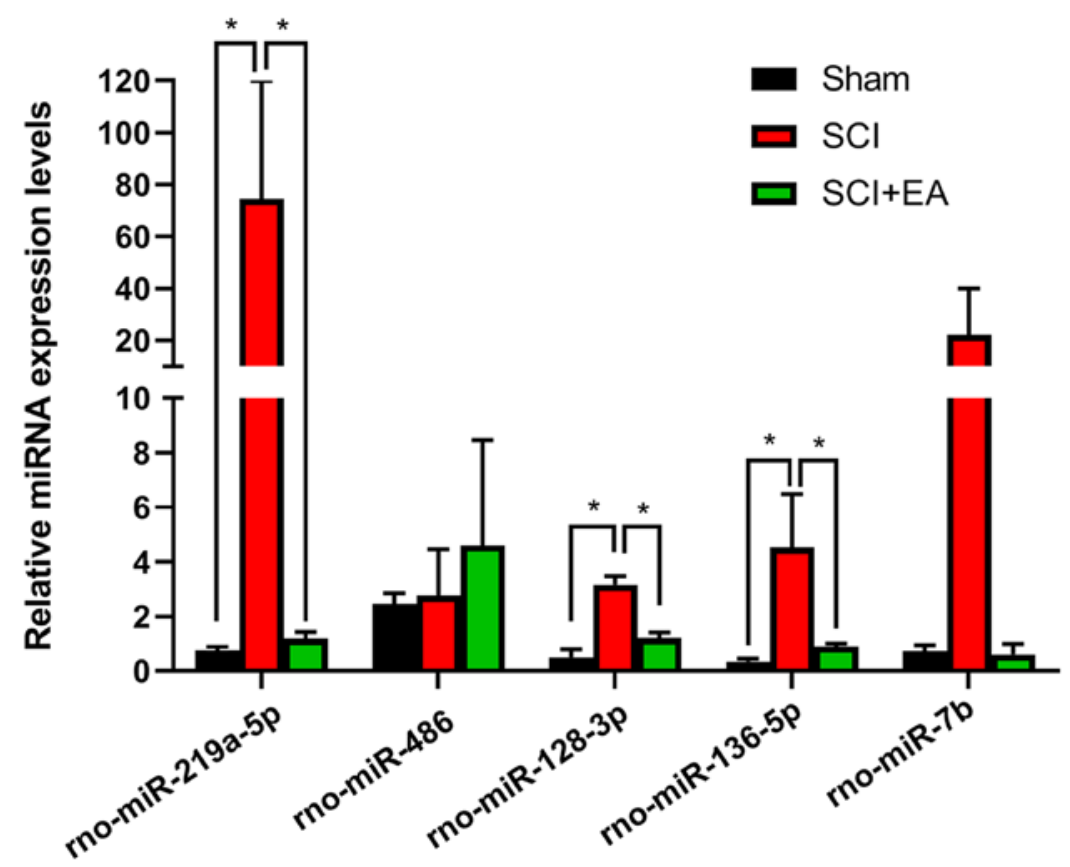

Figure 6. Validation of candidate differentially expressed miRNAs by RT-qPCR. Bar graph representing expression levels of 5 miRNAs identified by next-generation sequencing. Data are presented as the mean \pm SD of relative expression levels measured by RT-qPCR. $\mathrm{n}=3$. * $\mathrm{P}<0.05$. SCI, spinal cord injury; EA, electroacupuncture; miRNA, micro RNA; RT-qPCR, reverse transcription-quantitative PCR.

significant differential expression between the SCI+EA and SCI groups. Of the DE miRNAs, 139 were downregulated and 29 were upregulated in the EA+SCI group, compared with the SCI group. Statistical significance was defined by an adjusted $\mathrm{P}<0.05$ and $\mid \log _{2} \mathrm{FCl}>1$. A heatmap of the $168 \mathrm{DE}$ miRNAs with $\log _{2} \mathrm{FC}$ values ranked by the P-value indicated that the SCI+EA and SCI group rats could be differentiated based on DE miRNAs (Fig. 4A). The top 20 up- and downregulated miRNAs are shown in Fig. 4B.

Function and pathway analysis of predicted target genes of DE miRNAs. Based on the target gene prediction, the potential mRNAs of DE miRNAs were subjected to GO and KEGG enrichment analysis. The top 20 GO terms are shown in Fig. 5A. 'Phosphorylation' and 'Regulation of transcription, DNA-templated' were significantly enriched. KEGG analysis suggested that these predicted target genes were enriched in the 'Focal adhesion', 'Wnt signaling pathway' and 'Ras signaling pathway' (Fig. 5B). Thus, these pathways might have potential significance in SCI recovery with EA treatment.
Validation of candidate miRNA expression by RT-qPCR. To confirm the NGS results, five miRNAs, rno-miR-219a-5p, rno-miR-486, rno-miR-136-5p, rno-miR-128-3p and rno-miR-7b, with high fold change and high abundance were selected as candidate miRNAs and were screened as they or their target mRNAs were involved in SCI recovery (45-47). Compared with the SCI group, rno-miR-219a-5p, rno-miR-128-3p, and rno-miR-136-5p were significantly downregulated $(\mathrm{P}<0.05)$ in the sham and $\mathrm{SCI}+\mathrm{EA}$ groups. There was no significant difference in rno-miR-486 and rno-miR-7b between the Sham, SCI and SCI+EA groups (Fig. 6). The RT-qPCR validation results were generally consistent with the sequencing results (Table II), suggesting that the latter were reliable.

Analysis of the integrated miRNA-mRNA-pathway network. Five candidate miRNAs, namely rno-miR-219a-5p, rno-miR-486, rno-miR-136-5p, rno-miR-128-3p, and rno-miR-7b, and their respective target genes associated with the top enriched pathways were assembled in an 
A

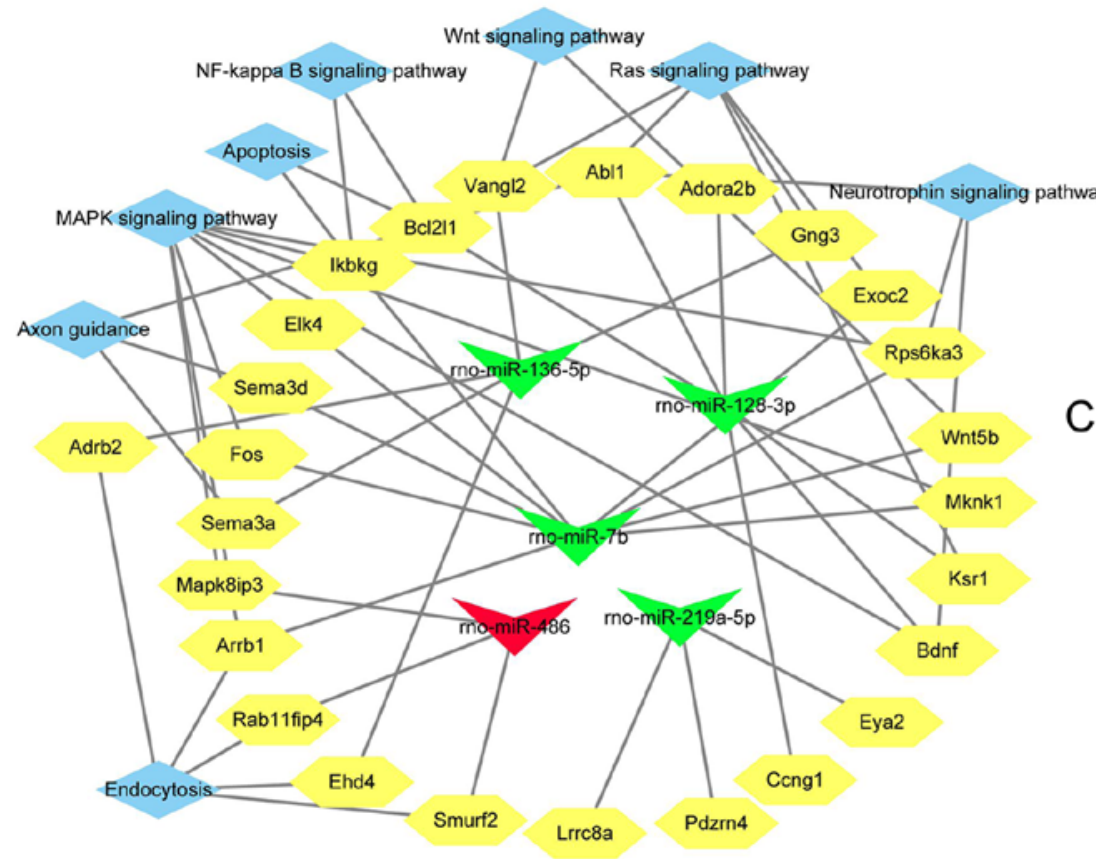

B
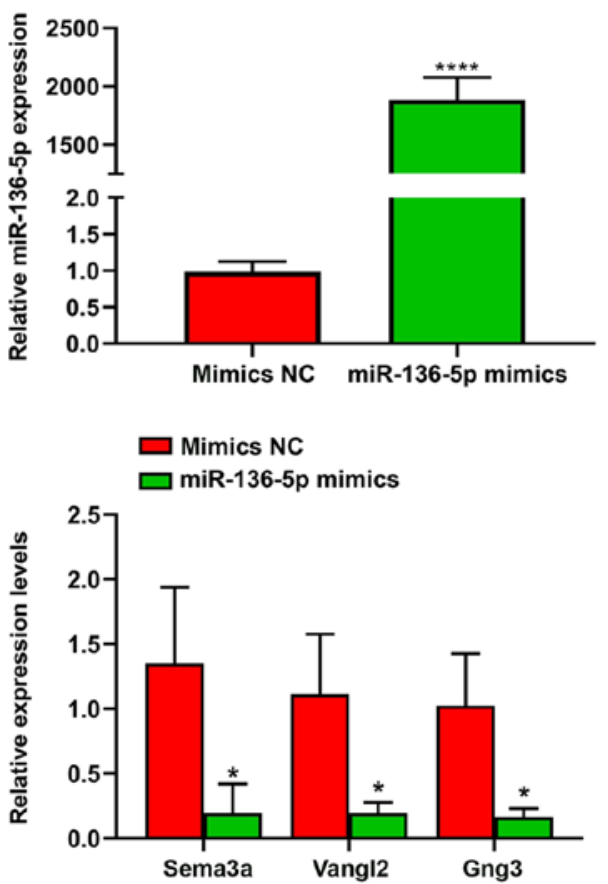

Figure 7. Target gene analysis of candidate miRNAs. (A) Predicted miRNA-mRNA-pathway network. miRNAs presented in green are downregulated, while those in red are upregulated in the SCI+EA group, vs. the SCI group. Target genes are represented by yellow hexagons. Blue diamonds represent signaling pathways. (B) Transfection efficiency of miR-136-5p mimics was verified by reverse transcription-quantitative PCR. (C) mRNA expression level of Sema3a, Vang12 and Gng3 in BV2 microglial cells. Data are presented as the mean \pm SD. $n=3$ in each group. ${ }^{*} \mathrm{P}<0.05$ and ${ }^{* * * * *} \mathrm{P}<0.0001$. SCI, spinal cord injury; EA, electroacupuncture; miR/miRNA, micro RNA; Sema3a, semaphoring 3A; Vang12, Van Gogh Drosophila-like planar cell polarity protein 2; Gng3, G protein subunit $\gamma 3$.

\section{A}

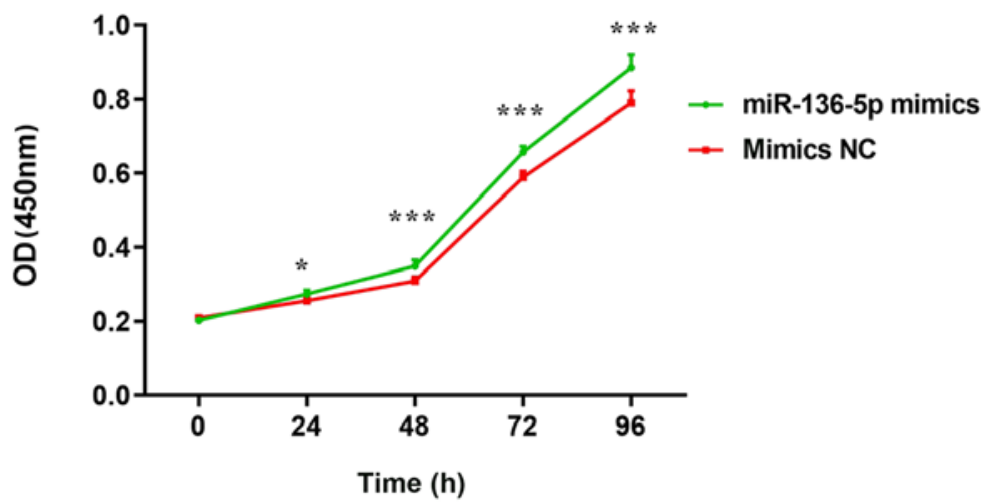

\section{B}

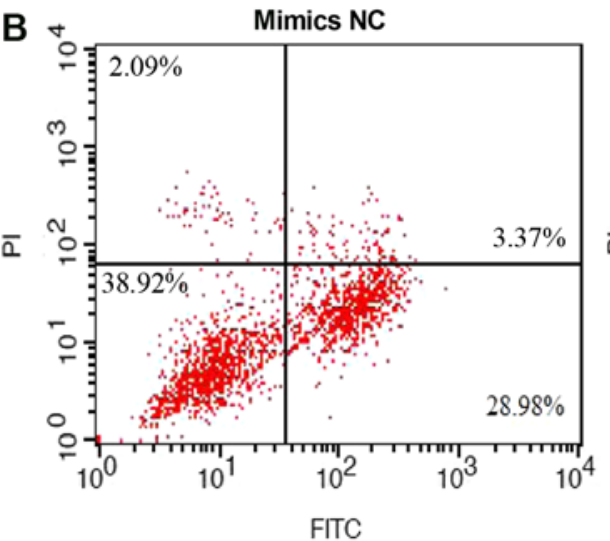

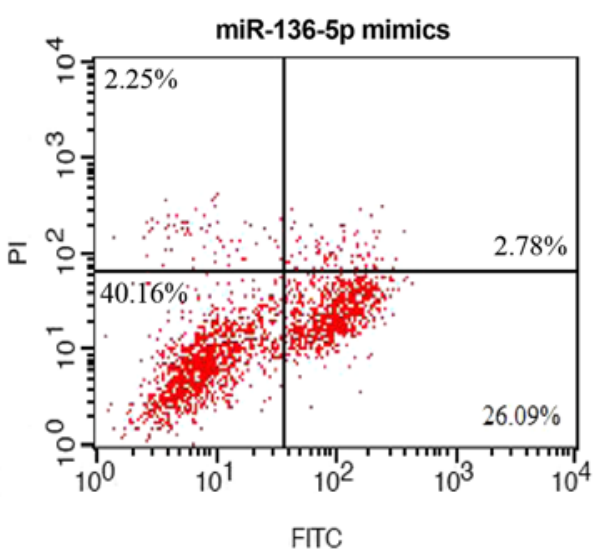

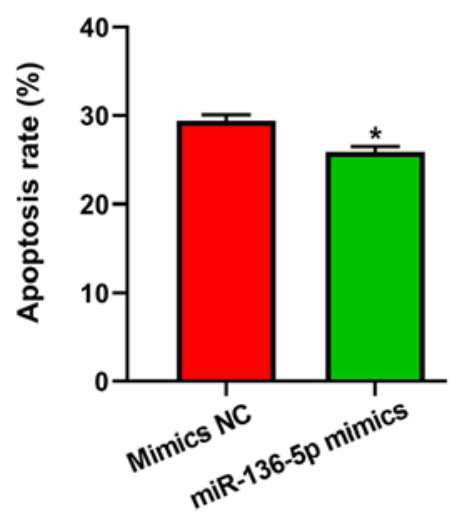

Figure 8. Effects of miR-136-5p on cell proliferation and apoptosis in BV2 microglial cells. (A) BV2 microglial cells were transfected with miR-136-5p mimics, and cell proliferation was quantified by administering Cell Counting Kit-8 after 0, 24, 48, 72 or $96 \mathrm{~h}$ of incubation with miR-136-5p mimics or NC mimics. OD was measured at $450 \mathrm{~nm}$ after $1 \mathrm{~h}$. Data are presented as the mean \pm SD. (B) Annexin V/PI double-staining method to detect microglial cell apoptosis in the NC mimic and miR-136-5p mimic groups. $\mathrm{n}=6$ in each group. ${ }^{*} \mathrm{P}<0.05$ and ${ }^{* * *} \mathrm{P}<0.001$ miR-136-5p mimics group vs. NC mimics group. OD, optical density; $\mathrm{NC}$, negative control; PI, propidium iodide; FITC, fluorescein isothiocyanate. 
integrated miRNA-mRNA pathway network. The terms 'Wnt signaling pathway', 'neurotrophin signaling pathway', 'NF- $\mathrm{B}$ signaling pathway' and 'MAPK signaling pathway' were identified as enriched pathways using this analysis (Fig. 7A). From the network, miR-136-5p targeted 'Wnt signaling pathway' through Van Gogh Drosophila-like planar cell polarity protein 2 (Vang12), the 'axon guidance' through semaphoring 3 A (Sema3a), and the 'Ras signaling pathway' through Vangl2 and G protein subunit $\gamma 3$ (Gng3). Moreover, miR-136-5p was selected for further study as it showed a significant difference in expression between the SCI and SCI+EA groups. The expression of three candidate target genes of miR-136-5p, including Sema3a, Vang12 and Gng3, was assessed by RT-qPCR in BV2 microglial cells transfected with miR-136-5p mimics. Compared with the mimics-NC, the expression of Sema3a, Vang12 and Gng3 was significantly downregulated in microglial cells transfected with the miR-136-5p mimics (Fig. 7B and C).

Effects of miR-136-5p on microglial cell proliferation and apoptosis. To observe the function of miR-136-5p on proliferative and apoptotic abilities, microglial cells were transfected with miR-136-5p. Cell proliferation was quantified using the CCK-8 method. Transfection with miR-136-5p mimics significantly promoted microglial cell proliferation, compared with mimics-NC (Fig. 8A). The effects of miR-136-5p on cell apoptosis were then analyzed by flow cytometry. Compared with the mimics-NC group, the number of apoptotic cells was significantly decreased in BV2 cells transfected with miR-136-5p mimics ( $\mathrm{P}<0.01$; Fig. 8B). These results indicated that $\mathrm{miR}-136-5 \mathrm{p}$ enhanced proliferation and inhibited the apoptosis of microglia cells.

\section{Discussion}

miRNAs are non-coding RNA molecules of 18-24 nucleotides that regulate gene expression by interacting with specific sequences of target mRNAs or promoters $(48,49)$. To date, several studies have analyzed the effect of miRNAs in injury and neuroprotection (50-52). Previous studies also demonstrated that the circulating microRNA profile may serve as a latent diagnosis biomarker and new target in the molecular treatment of SCI $(23,24)$. Other previous studies suggested that EA treatment improved hindlimb motor function of SCI rats $(36,53)$. However, analysis of the miRNA profile and functions affected by EA treatment in SCI rats has not been investigated.

In the present study, the effects of EA on miRNA expression following SCI were evaluated in rats. The present results suggested that EA treatment on rats with SCI led to miRNA dysregulation, thus affecting multiple processes that in many cases are associated with secondary damage from SCI and recovery of rats. The observed changes in expression mainly included an increased number of downregulated miRNAs. However, few miRNAs were upregulated. Progressive dysregulation of miRNAs has been reported in rats with SCI (54). In addition, Strickland et al (55) observed a similar increase in the number of downregulated miRNAs in the 14 days after SCI. Previous studies described the functional roles of the miRNAs that are dysregulated in rats with SCI, which are potentially regulated by co-expressed miRNAs $(56,57)$. These analyses indicated that changes in miRNA expression could affect numerous biological functions known to be altered in SCI rats.

A previous study demonstrated that miR-223 promoted neutrophil-mediated inflammation and aggravated SCI in the early stage after SCI (58). Furthermore, miRNA-136-5p upregulates $\mathrm{p}$-nuclear factor $\kappa \mathrm{B}(\mathrm{p}-\mathrm{NF}-\kappa \mathrm{B})$ expression by downregulating A20 expression, which causes astrocytes to produce inflammatory factors and chemokine factors, thus aggravating SCI (59). Recently, Deng et al (45) found that IL-1 $\beta$, IL- 6 , TNF- $\alpha$, interferon- $\alpha$, inhibitor of nuclear factor kappa B kinase subunit $\beta$, and $\mathrm{NF}-\kappa \mathrm{B}$ in SCI rats were upregulated, while A20 was downregulated following miR-136-5p overexpression. Under these conditions, inflammatory cell infiltration into the rat spinal cord increases, significantly aggravating injury. Silencing of miR-136-5p significantly reduces these changes in protein expression and ameliorates the inflammatory cell infiltration and spinal cord damage. Therefore, miR-136-5p might be a new target for the treatment of SCI (45). In the present study, miR-136-5p expression was decreased in EA-treated SCI rats, compared with the SCI group. In addition, Zhang et al (60) observed that miRNA-127 can regulate inflammation by activating the JNK and NF- $\kappa \mathrm{B}$ pathways. NF- $\mathrm{B}$ has different states (phosphorylated and dephosphorylated) and activity levels in different types of cells and tissues. NF- $\mathrm{NB}$ is a multidirectional transcription factor as well as the converging point of many signal transduction pathways. It plays an important role in immunity, inflammation, cell cycle regulation, cell proliferation and differentiation, and apoptosis (61).

Inflammatory reactions play an important role in SCI progression. The present study demonstrated that EA significantly improved inflammatory cell infiltration and inflammatory factor expression. Moreover, EA-induced DE miRNAs were mainly enriched in inflammation-related pathways, such as the aforementioned NF- $\kappa$ B pathway. Additionally, microglial cells are the main inflammatory cells in the brain and spinal cord. Previous studies used microglial cells to study the functional recovery of SCI $(62,63)$. Therefore, the contribution of miR-136-5p to EA-induced alleviation of inflammation was also evaluated in microglial cells in the present study. miR-136-5p enhanced proliferation and inhibited apoptosis of microglial cells, suggesting that miR-136-5p might be involved in EA treatment by modulating inflammation in microglial cells.

In conclusion, the present study provided an analysis of DE miRNAs in SCI rats treated with EA using high-throughput sequencing and described their functional interaction network, therefore providing an understanding of the mechanism and function of miRNAs in SCI rats. However, how miRNAs target mRNA to participate in the regulation of EA treatment through various signaling pathways remains to be elucidated.

\section{Acknowledgements}

Not applicable.

\section{Funding}

No funding was received. 


\section{Availability of data and materials}

The datasets used and/or analyzed during the current study are available from the corresponding author on reasonable request.

\section{Authors' contributions}

FD and JL designed and funded the present study. ZZ, HJL, HCL, JZ, KF, CC, FD and JL performed the experiments. ZZ, HJL, KF and CC analyzed the data. ZZ, HCL, JZ and KF conducted literature search. All authors prepared and revised the manuscript. All authors read and approved the final manuscript.

\section{Ethics approval and consent to participate}

All experiments were approved by The Institutional Animal Care and Use Committee of the Second Affiliated Hospital of Nanchang University and were performed according to the guidelines of The National Institutes of Health Guide for The Care and Use of Laboratory Animals.

\section{Patient consent for publication}

Not applicable.

\section{Competing interests}

The authors declare that they have no competing interests.

\section{References}

1. McDonald JW and Sadowsky C: Spinal-cord injury. Lancet 359 417-425, 2002

2. Sharif-Alhoseini M and Rahimi-Movaghar V: Animal models in traumatic spinal cord injury. Top Paraplegia 2014.

3. Gao L, Sun Y, Li J, Bai F and Li P: Effects of electroacupuncture in different time on variations of fractional anisotropy mean value of diffusion tensor tractogra-phy in spinal cord injured rats. Chin J Rehabil Theory Prac 20: 728-733, 2014.

4. Majdan M, Plancikova D, Nemcovska E, Krajcovicova L, Brazinova A and Rusnak M: Mortality due to traumatic spinal cord injuries in Europe: A cross-sectional and pooled analysis of population-wide data from 22 countries. Scand J Trauma Resusc Emerg Med 25: 64, 2017.

5. Blight AR,Leroy EC Jr and Heyes MP: Quinolinic acid accumulation in injured spinal cord: Time course, distribution, and species differences between rat and guinea pig. J Neurotrauma 14: 89-98, 1997.

6. Hall ED and Springer JE: Neuroprotection and acute spinal cord injury: A reappraisal. NeuroRx 1: 80-100, 2004.

7. Tator CH: Update on the pathophysiology and pathology of acute spinal cord injury. Brain Pathol 5: 407-413, 1995.

8. Dong J, Lu M, He X, Xu J, Qin J, Cheng Z, Liang B, Wang D and $\mathrm{Li} \mathrm{H}$ : Identifying the role of microRNAs in spinal cord injury. Neurol Sci 35: 1663-1671, 2014.

9. Ning B, Gao L, Liu RH, Liu Y, Zhang NS and Chen ZY: MicroRNAs in spinal cord injury: Potential roles and therapeutic implications. Int J Biol Sci 10: 997-1006, 2014.

10. Li J, Li L and Shen Y: Protective role of microRNA-219-5p inhibitor against spinal cord injury via liver receptor homolog-1/Wnt/ $\beta$-catenin signaling pathway regulation. Exp Ther Med 15: 3563-3569, 2018.

11. Bhalala OG, Srikanth M and Kessler JA: The emerging roles of microRNAs in CNS injuries. Nat Rev Neurol 9: 328-339, 2013.

12. Zheng Q, Zhang D, Yang YU, Cui X, Sun J, Liang C, Qin H, Yang X, Liu S and Yan Q: MicroRNA-200c impairs uterine receptivity formation by targeting FUT4 and 1,3-fucosylation. Cell Death Differ 24: 2161-2172, 2017.
13. Zeng Y, Liu JX, Yan ZP, Yao XH and Liu XH: Potential microRNA biomarkers for acute ischemic stroke. Int $\mathrm{J}$ Mol Med 36: 1639-1647, 2015.

14. Hinkel R, Penzkofer D, Zühlke S, Fischer A, Husada W, Xu QF, Baloch E, Van RE, Zeiher AM, Kupatt C and Dimmeler S: Inhibition of microRNA-92a protects against ischemia/reperfusion injury in a large-animal model. Circulation 128: 1066-1075, 2013.

15. Beermann J, Piccoli MT, Viereck J and Thum T: Non-coding RNAs in development and disease: Background, mechanisms, and therapeutic approaches. Physiol Rev 96: 1297-1325, 2016.

16. van Rooij E, Sutherland LB, Liu N, Williams AH, McAnally J, Gerard RD, Richardson JA and Olson EN: A signature pattern of stress-responsive microRNAs that can evoke cardiac hypertrophy and heart failure. Proc Natl Acad Sci USA 103: 18255-18260, 2006.

17. Zhao Y, Ransom JF, Li A, Vedantham V, von Drehle M, Muth AN, Tsuchihashi T, McManus MT, Schwartz RJ and Srivastava D: Dysregulation of cardiogenesis, cardiac conduction, and cell cycle in mice lacking miRNA-1-2. Cell 129: 303-317, 2007.

18. Bala S, Marcos M and Szabo G: Emerging role of microRNAsin liver diseases. World J Gastroenterol 15: 5633-5640, 2009.

19. Krutzfeldt J, Rajewsky N, Braich R, Rajeev KG, Tuschl T, Manoharan $M$ and Stoffel M: Silencing of microR NAs in vivo with 'antagomirs'. Nature 438: 685-689, 2005.

20. Jackson AL, Burchard J, Leake D, Reynolds A, Schelter J, Guo J, Johnson JM, Lim L, Karpilow J, Nichols K, et al: Position-specific chemical modification of siRNAs reduces 'off-target' transcript silencing. RNA 12: 1197-1205, 2006.

21. Rao P, Benito E and Fischer A: MicroRNAs as biomarkers for CNS disease. Front Mol Neurosci 6: 39, 2013

22. Wang W, Kwon EJ and Tsai LH: MicroRNAs in learning, memory, and neurological diseases. Learn Mem 19: 359-368, 2012.

23. Zhang T, Ni SF, Luo Z, Lang Y, Hu J and Lu H: The protective effect of microRNA-21 in neurons after spinal cord injury. Spinal Cord 57: 141-149, 2019.

24. Gao L, Dai C, Feng Z, Zhang L and Zhang Z: MiR-137 inhibited inflammatory response and apoptosis after spinal cord injury via targeting of MK2. J Cell Biochem 119: 3280-3292, 2017.

25. Bao N, Fang B, Lv H, Jiang Y, Chen F, Wang Z and Ma H: Upregulation of miR-199a-5p protects spinal cord against ischemia/reperfusion-induced injury via downregulation of ECE1 in rat. Cell Mol Neurobiol 38: 1293-1303, 2018.

26. Obermair FJ, Schröter A and Thallmair M: Endogenous neural progenitor cells as therapeutic target after spinal cord injury. Physiology (Bethesda) 23: 296-304, 2008.

27. Yan Q, Ruan JW, Ding Y, Li WJ, Li Y and Zeng YS: Electro-acupuncture promotes differentiation of mesenchymal stem cells, regeneration of nerve fibers and partial functional recovery after spinal cord injury. Exp Toxicol Pathol 63: 151-156, 2011.

28. Jiang SH, Tu WZ, Zou EM, Hu J, Wang S, Li JR, Wang WS, He R, Cheng RD and Liao WJ: Neuroprotective effects of different modalities of acupuncture on traumatic spinal cord injury in rats. Evid Based Complement Alternat Med 2014: 431580, 2014.

29. Park JH, Han JB, Kim SK, Park JH, Go DH, Sun B and Min BI: Spinal GABA receptors mediate the suppressive effect of electroacupuncture on cold allodynia in rats. Brain Res 1322: 24-29, 2010.

30. Aloe L and Manni L: Low-frequency electro-acupuncture reduces the nociceptive response and the pain mediator enhancement induced by nerve growth factor. Neurosci Lett 449: 173-177, 2009.

31. Park JH, Kim SK, Kim HN, Sun B, Koo S, Choi SM, Bae H and Min BI: Spinal cholinergic mechanism of the relieving effects of electroacupuncture on cold and warm allodynia in a rat model of neuropathic pain. J Physiol Sci 59: 291-298, 2009.

32. Min YJ, Cheng LH and Gao J: Comparative observations on three-unblocking acupuncture for the treatment of spinal cord injury in convalescent patients with paraplegia. Shanghai Zhenjiu Zazhi 32: 1010-1013, 2013.

33. Huang C, Wang Y, Han JS and Wan Y: Characteristics of electroacupuncture-induced analgesia in mice: Variation with strain, frequency, intensity and opioid involvement. Brain Res 945: $20-25,2002$. 
34. Lao L, Zhang RX, Zhang G, Wang X, Berman BM and Ren K: A para-metric study of electroacupuncture on persistent hyperalgesia and Fos protein expression in rats. Brain Res 1020: 18-29, 2004.

35. Lin JG, Lo MW, Wen YR, Hsieh CL, Tsai SK and Sun WZ: The effect of high and low frequency electroacupuncture in pain after lower abdominal surgery. Pain 99: 509-514, 2002.

36. Zhang JF, Li SS and Wu YC: Recovery of spinal cord injury following electroacupuncture in rats through enhancement of Wnt/ß-catenin signaling. Mol Med Rep 16: 2185-2190, 2017.

37. Filipp ME, Travis BJ, Henry SS, Idzikowski EC, Magnuson SA, Loh MY, Hellenbrand DJ and Hanna AS: Differences in neuroplasticity after spinal cord injury in varying animal models and humans. Neural Regen Res 14: 7-19, 2019.

38. Basso DM, Beattie MS and Bresnahan JC: A sensitive and reliable locomotor rating scale for open field testing in rats. J Neurotrauma 12: 1-21, 1995.

39. Ramayo-Caldas Y, Mach N, Esteve-Codina A, Corominas J, Castelló A, Ballester M, Estellé J, Ibáñez-Escriche N, Fernández AI, Pérez-Enciso M and Folch JM: Liver transcriptome profile in pigs with extreme phenotypes of intramuscular fatty acid composition. BMC Genomics 13: 547, 2012.

40. Wright GW and Simon RM: A random variance model for detection of differential gene expression in small microarray experiments. Bioinformatics 19: 2448-2455, 2003.

41. Turner DA: Miranda: A non-strict functional language with polymorphic types. In: Proc of a conference on functional programming languages and computer architecture, pp1-16, 1985.

42. Krüger J and Rehmsmeier M: RNAhybrid: MicroRNA target prediction easy, fast and flexible. Nucleic Acids Res 34 (Web Server issue): W451-W454, 2006.

43. Shannon P, Markiel A, Ozier O, Baliga NS, Wang JT, Ramage D, Amin N, Schwikowski B and Ideker T: Cytoscape: A software environment for integrated models of biomolecular interaction networks. Genome Res 13: 2498-2504, 2003.

44. Livak KJ and Schmittgen TD: Analysis of relative gene expression data using real-time quantitative PCR and the 2(-Delta Delta C(T)) method. Methods 25: 402-408, 2001.

45. Deng G, Gao Y, Cen Z, He J, Cao B, Zeng G and Zong S: miR-136-5p regulates the inflammatory response by targeting the IKK $\beta / \mathrm{NF}-\mathrm{\kappa B} / \mathrm{A} 20$ pathway after spinal cord injury. Cell Physiol Biochem 50: 512-524, 2018.

46. Knierim E, Hirata H, Wolf NI, Morales-Gonzalez S, Schottmann G, Tanaka Y, Rudnik-Schöneborn S, Orgeur M, Zerres K, Vogt S, et al: Mutations in subunits of the activating signal cointegrator 1 complex are associated with prenatal spinal muscular atrophy and congenital bone fractures. Am J Human Genet 98: 473-489, 2016

47. Matsuda M, Kanno H, Sugaya T, Yamaya S, Yahata K, Handa K, Shindo T, Shimokawa H, Ozawa H and Itoi E: Low-energy extracorporeal shock wave therapy promotes BDNF expression and improves functional recovery after spinal cord injury in rats. Exp Neurol 328: 113251, 2020.

48. Ambros V: The functions of animal microRNAs. Nature 431: 350-355, 2004

49. Bartel DP: MicroRNAs: Genomics, biogenesis, mechanism, and function. Cell 116: 281-297, 2004

50. Saugstad JA: MicroRNAs as effectors of brain function with roles in ischemia and injury, neuroprotection, and neurodegeneration. J Cereb Blood Flow Metab 30: 1564-1576, 2010.
51. Yip PK, Bowes AL, Hall JCE, Burguillos MA, Ip THR, Baskerville T, Liu ZH, Mohamed MAEK, Getachew F, Lindsay AD, et al: Docosahexaenoic acid reduces microglia phagocytic activity via miR-124 and induces neuroprotection in rodent models of spinal cord contusion injury. Human Mol Genet 28: 2427-2448, 2019.

52. Yan L, Shi E, Jiang X, Shi J, Gao S and Liu H: Inhibition of microRNA-204 conducts neuroprotection against spinal cord ischemia. Ann Thorac Surg 107: 76-83, 2019.

53. Min YJ, Ding LLQ, Cheng LH, Xiao WP, He XW, Zhang H, Min ZY and Pei J: Effect of electroacupuncture on the mRNA and protein expression of Rho-A and Rho-associated kinase II in spinal cord injury rats. Neural Regen Res 12: 110-116, 2017.

54. Yunta M, Nieto-Díaz M, Esteban FJ, Caballero-López M, Navarro-Ruíz R, Reigada D, Pita-Thomas DW, del Águila A, Muñoz-Galdeano T and Maza RM: MicroRNA dysregulation in the spinal cord following traumatic injury. PLoS One 7: e34534, 2012.

55. Strickland ER, Hook MA, Balaraman S, Huie JR, Grau JW and Miranda RC: MicroRNA dysregulation following spinal cord contusion: Implications for neural plasticity and repair. Neuroscience 186: 146-160, 2011.

56. Xing SM, Wang J, He X, Lai J, Shen L, Chen D, Fu K and Tan J: Identification of disease-related miRNAs based on co-expression network in spinal cord injury. Int Neurosci 125: 270-276, 2015.

57. Wei $\mathrm{H}$, Wang $\mathrm{C}$, Zhang $\mathrm{C}$, Li P, Wang $\mathrm{F}$ and Zhang Z: Comparative profiling of microRNA expression between neural stem cells and motor neurons in embryonic spinal cord in rat. Int J Dev Neurosci 28: 545-551, 2010.

58. Izumi B, Nakasa T, Tanaka N, Nakanishi K, Kamei N, Yamamoto R, Nakamae T, Ohta R, Fujioka Y, Yamasaki K and Ochi M: MicroRNA-223 expression in neutrophils in the early phase of secondary damage after spinal cord injury. Neurosci Lett 492: 114-118, 2011

59. He J, Zhao J, Peng X, Shi X, Zong S and Zeng G: molecular mechanism of MiR-136-5p targeting NF- $\mathrm{B} / \mathrm{A} 20$ in the IL-17-mediated inflammatory response after spinal cord injury. Cell Physiol Biochem 44: 1224-1241, 2017.

60. Zhang Z, Wan F, Zhuang Q, Zhang Y and Xu Z: Suppression of miR-127 protects PC-12 cells from LPS-induced inflammatory injury by downregulation of PDCD4. Biomed Pharmacother 96: 1154-1162, 2017.

61. Ahn KS, Sethi G and Aggarwal BB: Nuclear factor-kappa B: From clone to clinic. Curr Mol Med 7: 619-637, 2007.

62. Wang C, Wang Q, Lou Y, Xu J, Feng Z, Chen Y, Tang Q, Zheng G, Zhang Z, Wu Y, et al: Salidroside attenuates neuroinflammation and improves functional recovery after spinal cord injury through microglia polarization regulation. J Cell Mol Med 22: 1148-1166, 2018.

63. Zhang Y, Liu Z, Zhang W, Wu Q, Zhang Y, Liu Y, Guan Y and Chen X: Melatonin improves functional recovery in female rats after acute spinal cord injury by modulating polarization of spinal microglial/macrophages. J Neurosci Res 97: 733-743, 2019.

This work is licensed under a Creative Commons Attribution-NonCommercial-NoDerivatives 4.0 International (CC BY-NC-ND 4.0) License. 